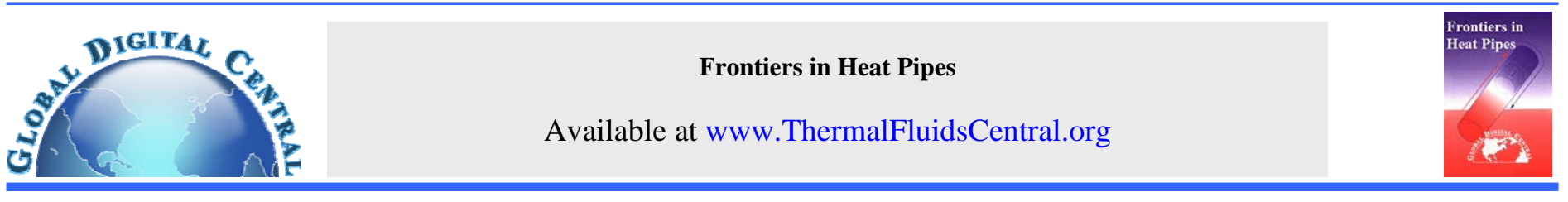

\title{
EXPERIMENTAL INVESTIGATION OF IN SITU PRESSURE MEASUREMENT OF AN OSCILLATING HEAT PIPE
}

\author{
Fritz F. Laun' and Brent S. Taft ${ }^{*}$ \\ Air Force Research Labs, Albuquerque, New Mexico, 87108, USA
}

\begin{abstract}
An investigation using in situ pressure measurements was conducted on an oscillating heat pipe (OHP) to better understand its chaotic nature and the relation between the frequency of oscillations and the thermal performance. The working fluid used was HPLC grade acetone with a 0.8 fill ratio by mass. Three different orientations were tested: top, horizontal, and bottom heating from 100 to $500 \mathrm{~W}$ in increments of $50 \mathrm{~W}$. An aluminum water block was used with water at approximately $0^{\circ} \mathrm{C}$ with a flow rate of $0.9 \mathrm{l} / \mathrm{min}$ for the condenser section of the OHP. The condenser and evaporator section were each fitted with a pressure transducer mounted perpendicular to the OHP channel. The pressure and temperature measurements were compared. Complex pressure wave forms were observed and a natural frequency could not be determined at the high filling ratio used.
\end{abstract}

Keywords: pulsating heat pipe, PHP, OHP, two-phase, thermal spreader

\section{INTRODUCTION}

It is estimated that future satellite missions will require a heat-rejection capability measured in the 100 's of W/cm², consistent with the general electronics trends of miniaturization and increasing power densities. Current generations of thermal spreaders available to deal with these large heat fluxes add significant weight, have a poor form factor, consume power, and can drastically increase the cost of manufacturing the final product. The passive thermal technologies available today are not able to deal with such high heat fluxes. However, a type of passive thermal system, the oscillating heat pipe (OHP), has the potential to successfully perform with high waste heat removal and minimal manufacturing cost.

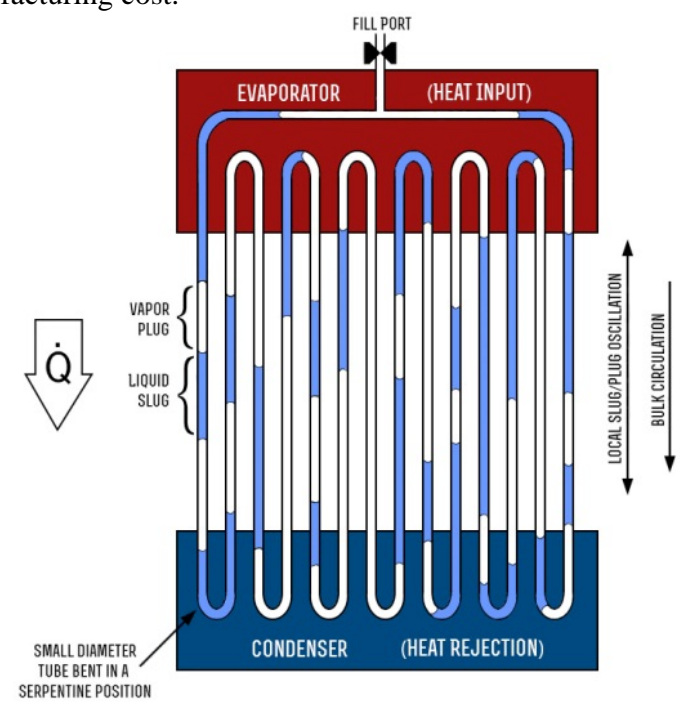

Fig. 1 Schematic of an oscillating heat pipe (Taft et al., 2013)

With the development of the OHP in 1990, a great deal of research has gone into understanding its unique fluid flow characteristics
(Akachi, 1990; Akachi 1993). However, electronics were less likely to be thermally limited and there was little need for a high heat flux thermal spreader. Recently attention has shifted to OHP research as electronics produce greater amounts of waste heat. The operating mechanisms of the OHP are still not well understood and further research must be done to create a viable thermal spreader.

The OHP, shown in Fig. 1, is a type of two-phase heat transfer device that is partially filled with a working fluid. The oscillatory motion of the working fluid efficiently transfers heat as a simplyformed, wickless heat pipe (Bhuwakietkumjohn and Rittidech, 2010). The two-phase oscillatory motion is induced by a pressure differential from the condenser (cold end) and the evaporator (hot end) that efficiently transfers heat. With adequate power, the temperature differential between the condenser and the evaporator can maintain an almost constant temperature. Typical OHPs exist as a single loop serpentine tubular design (T-OHP) or are machined on a flat-plate that is sealed with a cover sheet (FP-OHP). FP-OHPs have a better form factor and are able to deal with high heat fluxes (Borgenmeyer and Ma, 2007).

The primary operating mechanisms of classical heat pipes and OHPs differ substantially. OHP operation may be considered gravity independent at high power levels, while classic heat pipes are highly dependent on gravitational effects. Classic heat pipes require an intricate wick structure to promote capillary action to transport liquid back to the condenser while OHPs do not, greatly reducing the manufacturing cost (Dolgirev et al., 2003). For high heat flux applications OHPs have a greater potential for successful operation than classic heat pipes (Zuo et al., 2001). The heat transfer process in a classic heat pipe is primarily caused by latent heat transfer, while the OHP uses the phase change heat transfer to create the oscillatory motion, resulting in sensible heat that accounts for the bulk of heat transfer. These unique features make the OHP an ideal solution to future thermal cooling needs as power densities continue to increase. This paper investigates the pressure oscillations created inside the internal OHP channels due to the two-phase motion of the working fluid. A brief summary of existing literature is presented before discussing the experimental setup, results, and conclusion. It was found

\footnotetext{
*Corresponding author, Email: afrl.rvsv@kirtland.af.mil
} 
that a dominate frequency of oscillations in the OHP did not exist and for a single temperature oscillation there are many pressure oscillations present.

\section{BACKGROUND}

Experimental and numerical investigations have been conducted to better characterize the pressure mechanism during OHP operation. Miyazaki and Akachi (1996) varied the heat flux and charging ratio to study the pressure oscillation characteristics of an OHP. Oscillation waves of long liquid slugs and vapor plugs were observed. An analytical model was then developed and it was determined that better heat transfer performance was achieved when frequency and amplitude of pressure oscillations was increased and decreased, respectively.

Kim et al. also varied the heat flux and charging ratio in an effort to better understand the pressure oscillation characteristics (Kim et al., 2003). Experimental results were able to quantify a frequency of pressure oscillations between $0.1 \mathrm{~Hz}$ and $1.5 \mathrm{~Hz}$ at a charging ratio of $40 \%$ by volume. It was found that when the pressure waves were symmetric and sinusoidal the heat transfer performance was improved. However, at 20 and $80 \%$ fill rates the pressure wave forms were too complicated and thus a fundamental frequency could not be found and heat transfer performance was reduced. Suzuki (2000) studied the temperature oscillation characteristics of a copper OHP using water as a working fluid. The frequency of the temperature oscillations was found to be proportional to the effective thermal conductivity. A relation was developed between the effective thermal conductivity and the frequency of the temperature oscillations.

\section{EXPERIMENTAL SETUP}

A FP-OHP design, as shown in Fig. 2, was constructed as an embedded OHP in an aluminum structural panel. The OHP has a total of 20 turns and an overall channel length of $20 \mathrm{~m}$. Traditionally an OHP may be manufactured in two separate pieces, later brazed together. However, ultrasonic consolidation (UC) was used to manufacture the OHP. UC is an additive/subtractive manufacturing technique that is ideally suited for the production of structurally integrated OHPs. UC allows for the creation of high strength materials with internal features that significantly exceed the strength to weight ratio of many current aerospace materials. A true metallurgic bond is created using UC deposition and CNC removal.

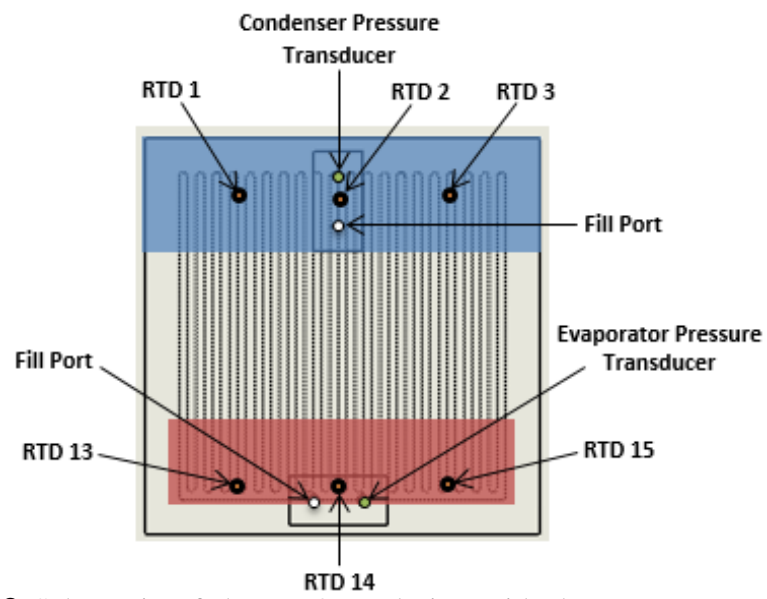

Fig. 2 Schematic of the FP-OHP design with the evaporator section highlighted in red and the condenser section in blue

In order to read pressure measurements inside the OHP, Swagelok VCR fittings and Omega pressure transducers were integrated into the panel in both the condenser and evaporator section. After leak testing using a helium leak detector to a leak rate of $10 \mathrm{E}-7 \mathrm{~atm} / \mathrm{cc} / \mathrm{sec}$, a vacuum (3E10-3 Torr) was pulled on the sealed OHP and acetone (high performance liquid chromatography grade) was added with 0.8 fill ratio by mass $( \pm 0.01)$. The high fill ratio was used to help decrease orientation dependency, ensuring liquid was always present in the evaporator during startup.

The channel diameter used, $1.3 \times 1.3 \mathrm{~mm}^{2}$, adheres to the maximum allowable diameter for liquid to form vapor bubbles in a capillary tube when using acetone as a working fluid (Taft et al., 2012):

$$
D_{\text {max }}=1.84 \sqrt{\frac{\sigma}{g\left(\rho_{l}-\rho_{v}\right)}}
$$

\section{METHOD}

The temperature differential of the OHP was measured using the experimental setup shown in Fig. 3. The system consisted of power supply, cooling bath, heater, aluminum water block, and data acquisition system (DAQ). Water was circulated through the aluminum water block at $0.9 \mathrm{l} / \mathrm{min}$ using a submergible pump in an ice bath. Heating and cooling were conducted on an area of $8 \times 30 \mathrm{~cm}^{2}$ and $15 \mathrm{x}$ $30 \mathrm{~cm}^{2}$, respectively. The adiabatic section was approximately $7.5 \mathrm{~cm}$ in length. Thermal paste (Artic Silver 5) was used as the thermal interface material between all contact surfaces. Four C-clamps were used with insulating pads to apply clamping pressure for the OHP to both the water block and the heater.

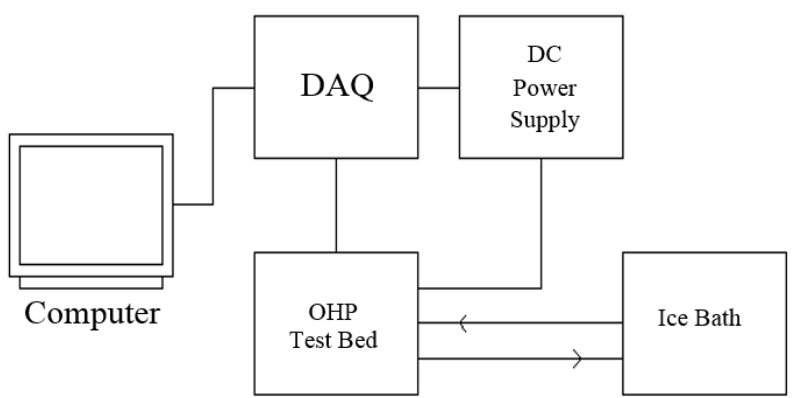

Fig. 3 Schematic of oscillating heat pipe experimental setup

A total of 16 thin film RTDs (100 Ohm) were placed at the surface of the OHP with an uncertainty of $\pm 0.75^{\circ} \mathrm{C}$ and a response time of approximately $250 \mathrm{~ms}$ (90\%). Temperature measurements were recorded at $10 \mathrm{~Hz}$ using a National Instruments data acquisition system with a customized Virtual Instrument (VI). The heat input was provided with a Lambda 150-10 power supply with a resolution of $\pm 0.01 \mathrm{~W}$. A test frame capable of horizontal and vertical orientations was used to support the OHP, heaters, and water block. High temperature foam insulation was used to insulate the system from the surrounding environment. Pressure measurements were recorded using two Omega pressure transducers, $0-0.2$ and $0-3.4 \mathrm{MPa}$, in the condenser and evaporator section of the OHP. Pressure readings had an uncertainty of \pm 0.7 and $1.7 \mathrm{kPa}$ for the condenser and evaporator section, respectively.

Heat input was increased from an initial $100 \mathrm{~W}$ in increments of 50 $\mathrm{W}$ to a maximum power output of $500 \mathrm{~W}$. The power was measured using a voltage divider and current measurement card and recorded at $10 \mathrm{~Hz}$. Each power level was held until a steady state condition was achieved and was then recorded for approximately five minutes. This procedure was performed for each orientation of the OHP three separate times to effectively produce a range of thermal resistances at each power level and orientation. This repetition helps to account for the variability in OHP performance resulting from the OHPs chaotic nature.

\section{RESULTS AND DISCUSSION}

The thermal resistance of the OHP was calculated by Eq. (2) over a 
period of five minutes of steady state conditions.

$$
R_{\text {OHP }}=\frac{1}{3 P}\left[\sum_{i=1}^{3} R T D_{i}-\sum_{i=13}^{15} R T D_{i}\right]
$$

where $R T D_{1-3}$ and $R T D_{13-15}$ are located in the evaporator and condenser, respectively and $P$ is the power input. The percent uncertainty in the calculated thermal resistance was calculated to be approximately $2 \%$.

Oscillations began at a power level of $200 \mathrm{~W}$, the condenser section data is shown in detail in Fig. 4. It can be seen that as the temperature readings from the RTDs increased, the pressure readings began to oscillate, indicating the movement and oscillations of liquid slugs and vapor plugs. As the temperature readings decreased, the pressure oscillations ceased as there was no longer enough energy to drive the oscillating motion. It can be seen that for one oscillation of an RTD there are many oscillations of liquid slugs and vapor plugs, creating the forced convection in the channel of the OHP that transfers sensible heat while phase change is the driving force, adding latent heat transfer.

The RTD measurements are damped due to the $1.6 \mathrm{~mm}$ wall between it and the OHP working fluid and are not a good indicator of actual oscillatory movement of liquid slugs and vapor plugs. The vapor plugs located in the condenser section are correlated with a decrease in the condenser temperature indicating a substantially decreased heat transfer compared to the oscillation of liquid slugs.

The theoretical saturation pressure of acetone may be compared to the observed pressure measurements at a given temperature. For comparison, at room temperature $\left(\sim 21^{\circ} \mathrm{C}\right)$ the OHP has a measured pressure of approximately $46.9 \mathrm{kPa}$ in both the condenser and evaporator sections. The saturation pressure of acetone is $25.7 \mathrm{kPa}$ at $21^{\circ} \mathrm{C}$ indicating that there may have been outgassing after the filling procedure. Air is more likely to be trapped in the pressure transducers as they are mounted above and perpendicular to the OHP channels. As the temperature of the acetone increased the difference between the theoretical and measured value of the pressure decreased. This may have been caused by the chaotic movement of the OHP dispersing any air pockets throughout the system. However, the OHP internal pressure at room temperature was consistent at $46.9 \mathrm{kPa}$ for the entire duration of testing and several months later. It is most likely a common occurrence for OHPs to have a slight amount of air inside after filling, but simply cannot be reported in the majority of literature as pressure transducers are not commonly placed in OHPs after the filling process.

As the power input to the OHP increased the pressure drop caused by liquid slugs became more consistent and increased in frequency. This also corresponded to the frequency of temperature oscillations increasing with the increase of power. At every power level the condenser temperature always increased with the presence of liquid slugs and decreased when only vapor was present. The pressure difference between liquid slugs and vapor plugs at each power level remained fairly constant at approximately $24.1 \mathrm{kPa}$ as the overall pressure increased due to the increased temperature.

The thermal resistance of the OHP decreased as the power level increased, as shown in Error! Reference source not found.. However, since three trials were used at each orientation and power level a range of thermal resistances was created. Overall the range of thermal resistance decreased as the power level increased as oscillations became more consistent. It was found that before oscillatory startup at low power levels (100 to $200 \mathrm{~W}$ ) the bottom heating had better thermal performance as it created natural convection as a themosyphon. Once oscillations began $(200 \mathrm{~W})$ the orientation had little effect on thermal resistance of the OHP. This may have been caused by the high fill ratio ( 0.8 by mass) and there was too much liquid in the system, hindering performance.

\section{A Fourier transformation was performed on the pressure oscillations in an attempt to find the natural frequency. The frequency of the pressure oscillations for the $\mathbf{2 0 0}$}

and $500 \mathrm{~W}$ tests in the horizontal orientation are shown in

Fig. 6. It can been seen that there was no natural frequency found. This may be due to the OHP being over filled.

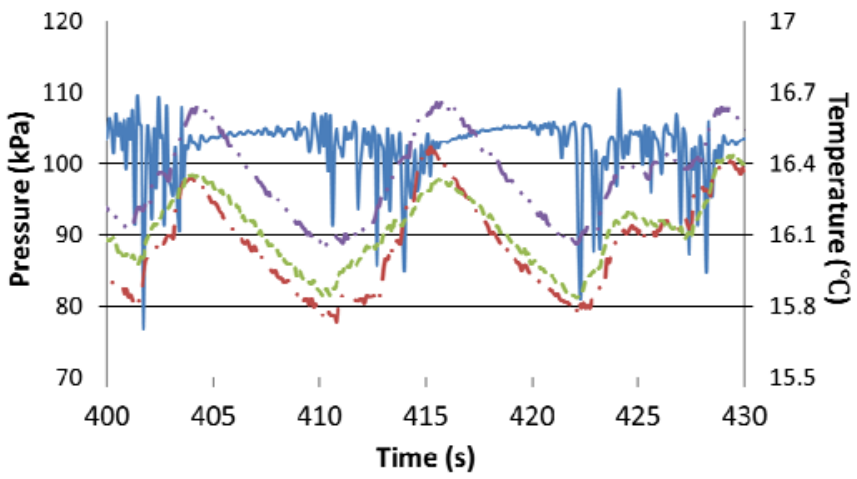

(a) $q=200 \mathrm{~W}$

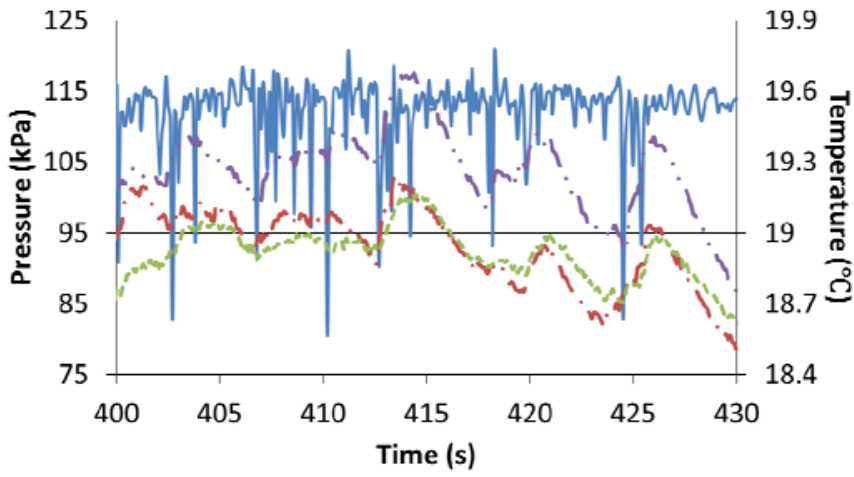

(b) $q=250 \mathrm{~W}$

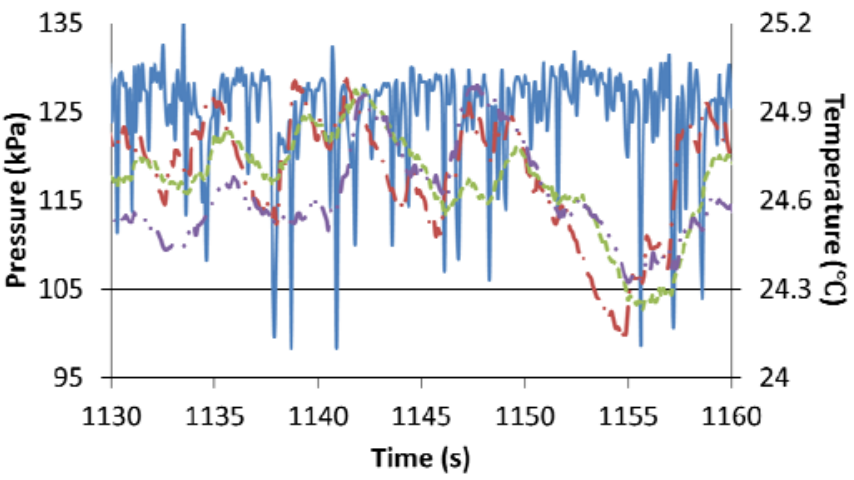

(c) $q=300 \mathrm{~W}$

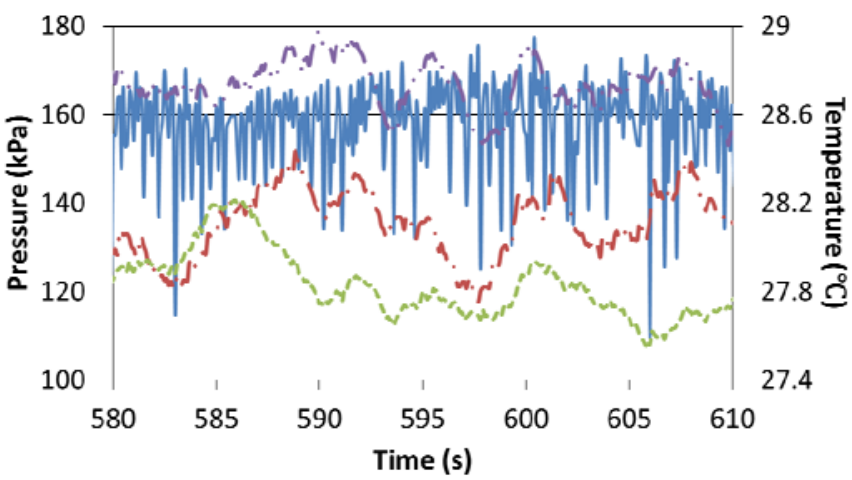

(d) $q=500 \mathrm{~W}$ 
Fig. 4 Pressure and temperature measurements in the condenser section of the OHP at (a) $200 \mathrm{~W}$, (b) $250 \mathrm{~W}$, (c) $300 \mathrm{~W}$, and (d) $500 \mathrm{~W}$ in the horizontal orientation

A phenomenon also observed by Kim et al., where it was found that at high fill ratios the OHP pressure wave forms were too complicated and a fundamental frequency could not be found (Kim et al., 2003).

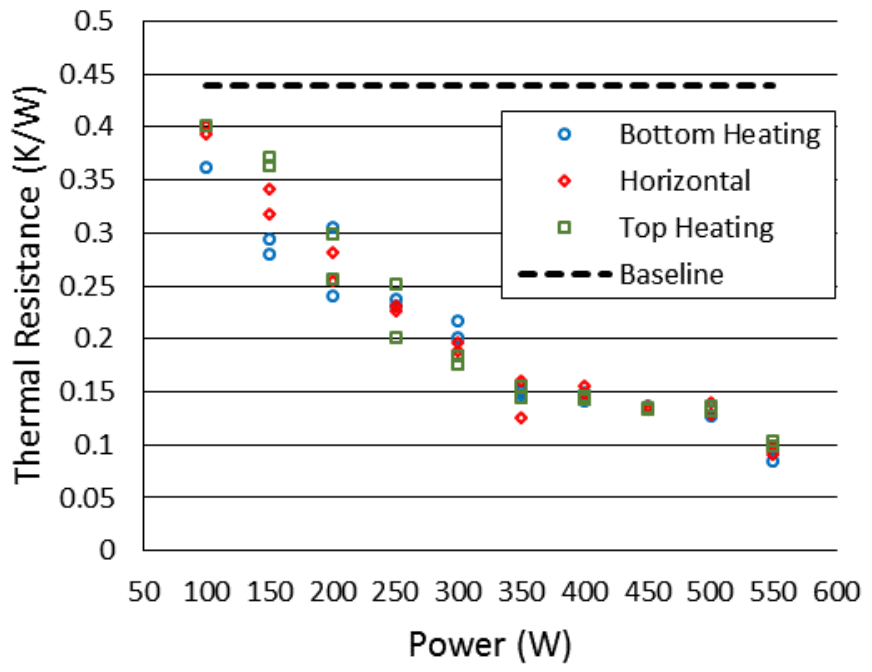

Fig. 5 Thermal resistance of the OHP for various power levels and orientations

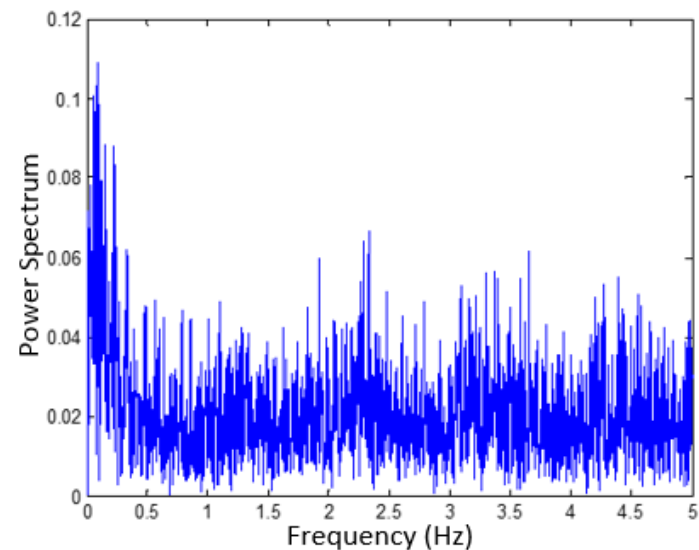

(a) $q=200 \mathrm{~W}$

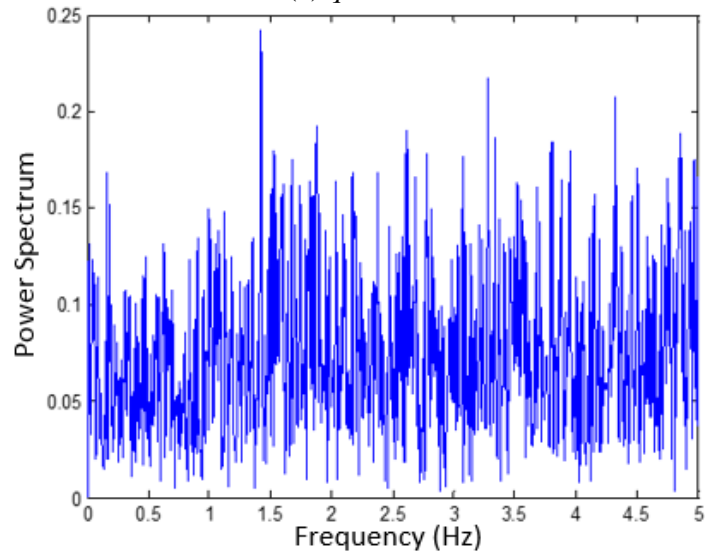

(b) $q=500 \mathrm{~W}$

Fig. 6 Power spectra for the pressure oscillations of the OHP at (a) 200 $\mathrm{W}$ and (b) $500 \mathrm{~W}$ in the horizontal orientation.

\section{CONCLUSIONS}

It is important to find a working relationship between pressure and thermal performance in order to better quantify an optimum fill ratio for OHPs and better understand their chaotic nature. In this study, a definitive correlation between the frequency of pressure oscillations and the heat transfer performance of an OHP was not found. The pressure wave forms were too complicated and a natural frequency could not be found at a high filling ratio. It is worth pursuing in future research the effect of fill ratio on the frequency of pressure oscillations and the heat transfer performance of an OHP.

\section{NOMENCLATURE}

$\begin{array}{ll}C & \text { conductance }(\mathrm{W} / \mathrm{K}) \\ P & \text { power input }(\mathrm{W}) \\ P & \text { pressure }(\mathrm{Pa}) \\ q & \text { heat }(\mathrm{W}) \\ R & \text { thermal resistance }(\mathrm{K} / \mathrm{W}) \\ T & \text { temperature }\left({ }^{\circ} \mathrm{C}\right) \\ & \\ \text { Greek Symbols } \\ \rho & \text { density }\left(\mathrm{kg} / \mathrm{m}^{3}\right) \\ \sigma & \text { surface tension }(\mathrm{N} / \mathrm{m}) \\ & \\ \text { Subscripts } & \\ l & \text { liquid } \\ \text { OHP } & \text { oscillating heat pipe } \\ v & \text { vapor }\end{array}$

\section{REFERENCES}

Akachi, H., 1990, "Structure of a Heat Pipe," U.S. Patent No. 4,921,041.

Akachi, H., 1993, "Structure of Micro-Heat Pipe," U.S. Patent No. 5219020.

Borgenmeyer, B., and Ma, H.B., 2007, "Experimental Investigation of Oscillating Motions in a Flat Plate Pulsating Heat Pipe," Journal of Thermophysics and Heat Transfer, 21(2), pp.405-409. http://dx.doi.org/10.2514/1.23263

Kim, J.S., Bui, N., Jung, H.S., and Lee, W.H., 2003, "The Study on Pressure Oscillation and Heat Transfer Characteristics of Oscillating Capillary Tube Heat Pipe," Journal of Mechanical Science and Technology, Vol. 17, No. 10, October 1, pp. 1533-1542.

Miyazaki, Y. and Akachi, H., 1996, "Heat Transfer Characteristics of Looped Capillary Heat Pipe," Proceeding of the 5th International Heat Pipe Symposium, Melbourne, pp. 378--383.

Bhuwakietkumjohn, N. and Rittidech, S., 2010, "Internal Flow Patterns on Heat Transfer Characteristics of a Closed-Loop Oscillating HeatPipe with Check Valves using Ethanol and a Silver Nano-Ethanol Mixture," Experimental Thermal and Fluid Science, Volume 34, Issue 8, Pages 1000-1007.

http://dx.doi.org/10.1016/j.expthermflusci.2010.03.003

Suzuki, O., 2000-5, 'Heat transfer characteristics of a Bubble-Driven Capillary Heat Pipe,"37th National Heat Transfer Symposium of Japan, pp. 35--36.

Taft, B.S., 2013, "Non-Condensable Gases and Oscillating Heat Pipe Operation," Frontiers in Heat Pipes, Vol. 4, 013003 http://dx.doi.org/10.5098/fhp.v4.1.3003 
Taft, B.S., Williams, A.D., and Drolen, B.L., 2012, "Review of Pulsating Heat Pipe Working Fluid Selection," Journal of Themophysics and Heat Transfer, Vol. 26, No. 4, pp. 651-656. http://dx.doi.org/10.2514/1.T3768

Dolgirev, Y.E., Gerasimov, Y.F., and Melkikh, A.V., 2003, "Theoretical and Experimental Study of Oscillating Heat Pipes with Few Turns," Journal of Engineering Physics and Thermophysics, Vol. 76, No. 5, September, pp. 996-1000.
http://dx.doi.org/10.1023/B:JOEP.0000003212.51653.4a

Zuo, Z.J., North , M.T., and Wert, K.L., 2001, "High Heat Flux Heat Pipe Mechanism for Cooling Of Electronics," IEEE Transactions on Components and Packaging Technologies, Vol. 24, No. 2, June, pp. 220-225.

http://dx.doi.org/10.1109/6144.926386 